\title{
PENGARUH KOMITMEN ORGANISASIONAL, GAYA KEPEMIMPINAN TRANSFORMASIONAL, DAN KOMPENSASI FINANSIAL TERHADAP SEMANGAT KERJA KARYAWAN PERUSAHAAN LOGISTIK
}

\author{
Made Febriani ${ }^{1}$ \\ I Wayan Gede Supartha ${ }^{2}$ \\ ${ }^{1,2}$ Fakultas Ekonomi dan Bisnis Universitas Udayana (UNUD), Bali, Indonesia \\ e-mail: febriani_88@yahoo.co.id

\begin{abstract}
ABSTRAK
Semangat kerja karyawan dapat menentukan keunggulan kompetitif bagi perusahaan. Penelitian ini bertujuan untuk mengetahui pengaruh komitmen organisasional, gaya kepemimpinann transformasional, dan kompensasi finansial terhadap semangat kerja karyawan. Penelitian dilakukan di PT. Surya Cemerlang Logistik. Jumlah responden dalam penelitian ini adalah 38 orang. Data dikumpulkan melalui kuesioner dengan indikator yang diukur dengan Skala Likert. Teknik analisis yang digunakan adalah Regresi Linier Berganda. Hasil penelitian menunjukkan variabel komitmen organisasional, gaya kepemimpinan transformasional, dan kompensasi finansial masing-masing berpengaruh positif dan signifikan terhadap semangat kerja karyawan di PT. Surya Cemerlang Logistik. Diantara ketiga variabel bebas yang diteliti, kompensasi finansial merupakan variabel yang memiliki pengaruh dominan terhadap semangat kerja karyawan.
\end{abstract}

Kata kunci: semangat kerja, komitmen, kepemimpinan transformasional, kompensasi finansial

\begin{abstract}
An increased employee morale provides a competitive advantage for a company. The purpose of this study was to determine the effect of organizational commitment, transformational leadership, and financial compensation to employee morale. This research take place in PT. Surya Cemerlang Logistik. The number of respondents from PT. Surya Cemerlang Logistik employees in this research is 38 employees. Data were collected by questionnaire and then measured using Likert Scale. Multiple Linear Regression is used to analyze the variable. The result indicates that each variable organizational commitment, transformational leadership, and financial compensation partially has positive and significant impact on employee morale at PT. Surya Cemerlang Logistik. Among the three variables, finansial compensation is a variable that has the most dominant influence on employee morale PT. Surya Cemerlang Logistik.
\end{abstract}

Keyword: employee morale, organizational commitment, transformational leadership, financial compensation 


\section{PENDAHULUAN}

Perkembangan ekonomi global yang semakin pesat menuntut standar yang lebih tinggi untuk perusahaan logistik. Di Bali perusahaan logistik masih sangat diperlukan mengingat Bali merupakan daerah pariwisata dan wisatawan yang berdatangan tidak hanya untuk liburan melainkan juga untuk melakukan kegiatan bisnis. Perusahaan logistik merupakan perusahaan yang menyediakan jasa pengiriman barang serta menyediakan jasa penyewaan gudang bagi perusahaan lain untuk menyimpan barangnya. Usaha yang dilakukan pemerintah dalam perkembangan ekonomi global dapat dikatakan sudah baik. Hal tersebut akan membawa keuntungan bagi perusahaan logistik karena akan menambah peluang dalam hal jasa pengiriman barang serta penyewaan gudang. Faktor penentu keberhasilan organisasi juga berasal salah satunya dari sumber daya manusia, untuk itu diperlukan sumber daya manusia yang benar-benar memiliki skill, semangat kerja serta tanggung jawab tinggi dalam memberikan pelayanan yang maksimal.

Melihat jangkauan perusahaan logistik yang sangat luas tidak hanya di dalam negeri namun hingga ke luar negeri, maka perusahaan wajib memberi perhatian terhadap faktor yang dapat mempengaruhi semangat kerja karyawan. Karyawan yang tinggi semangat kerjanya akan selalu berusaha untuk mencapai tujuan organisasi semaksimal mungkin. Siagian (2007:42) menyatakan bahwa dengan meningkatnya semangat kerja, maka pekerjaan dapat selesai lebih cepat, tingkat ketidakhadiran dapat dikurangi, kerusakan barang akan berkurang, dan memperkecil kemungkinan perpindahan karyawan. Dijelaskan lebih lanjut bahwa 
seorang pemimpin harus dapat mewujudkan bahkan meningkatkan semangat kerja karyawannya.

Komitmen organisasional adalah variabel yang mempengaruhi semangat kerja. Komitmen organisasional ialah sikap loyal yang membuat karyawan untuk tetap bekerja dalam suatu organisasi Lamba dan Choudary (2013). Setyaningdyah et al. (2015) menyatakan komitmen organisasional berkontribusi untuk meningkatkan semangat kerja karyawan. Srivalli dan Kota (2016) menyatakan komitmen organisasional merupakan sikap yang membuat karyawan melaksanakan pekerjaan secara efektif. Hasil penelitian Trisna dan Sintaasih (2016) menunjukkan bahwa secara parsial komitmen organisasional berpengaruh positif dan signifikan terhadapa semangat kerja dan mampu menciptakan iklim kerja yang profesional.

Variabel lainnya yang mempengaruhi semangat kerja yaitu kepemimpinan transformasional. Kepemimpinan transformasional berdasarkan pendapat Northouse (2013:177) adalah gaya kepemimpinan yang berdasar pada proses dimana orang terlibat dengan orang lain serta menciptakan suatu hubungan yang meningkatkan motivasi baik dalam diri pemimpin maupun pengikutnya. Shim et al. (2015) menyatakan jika menerapkan kepemimpinan transformasional dapat menggerakkan karyawan untuk bekerja lebih giat. Yingxiu Yang (2014) menyatakan kepemimpinan tranformasional perlu diterapkan karena akan memunculkan ide-ide yang menguntungkan. Yudi dan Artha (2014) berdasarkan penelitiannya gaya kepemimpinan transformasional memiliki pengaruh positif signifikan terhadap semangat kerja karyawan. 
Variabel lain yang turut memiliki pengaruh terhadap semangat kerja karyawan yakni pemberian kompensasi finansial. Kompensasi finansial ialah pendapatan berupa uang yang diterima oleh karyawan sebagai imbalan atau jasa yang diberikan oleh perusahaaan (Hasibuan, 2007:118). Boone and Kurtz menyatakan kompensasi finansial merupakan penghargaan berupa uang yang mencakup gaji dan ditambah dengan tunjangan-tunjangan. Linz et al. (2006) menemukan kompensasi finansial berpengaruh positif signifikan terhadap semangat kerja karyawan.

PT. Surya Cemerlang Logistik adalah perusahaan logistik di Bali, sebanyak 38 karyawan memiliki tanggung jawab dan beban kerja yang bervariasi sehingga dibutuhkan SDM yang berkualitas dan berkomitmen tinggi dalam rangka mencapai tujuan organisasi. Banyaknya tanggung jawab dan beban kerja yang tinggi akan membuat karyawan tidak semangat dalam bekerja.

Tabel 1 menunjukkan adanya indikasi rendahnya semangat kerja karyawan yang diperoleh berdasarkan dari hasil wawancara awal terhadap 10 karyawan.

Tabel 1.

Hasil Pra Survei

\begin{tabular}{|c|c|c|c|c|c|c|c|c|c|}
\hline \multirow[t]{2}{*}{ No } & \multirow[t]{2}{*}{ Pernyataan } & \multicolumn{5}{|c|}{ Skor Jawaban } & \multirow{2}{*}{$\begin{array}{l}\text { Jumlah } \\
\text { Skor }\end{array}$} & \multirow{2}{*}{$\begin{array}{l}\text { Rata- } \\
\text { Rata }\end{array}$} & \multirow[t]{2}{*}{ Ket } \\
\hline & & 1 & 2 & 3 & 4 & 5 & & & \\
\hline 1 & $\begin{array}{l}\text { Tingkat kehadiran saya sudah } \\
\text { baik }\end{array}$ & 0 & 0 & 0 & 9 & 1 & 41 & 4,10 & Tinggi \\
\hline 2 & $\begin{array}{l}\text { Pekerjaan yang saya lakukan } \\
\text { selesai tepat waktu }\end{array}$ & 0 & 0 & 0 & 8 & 2 & 42 & 4,20 & Tinggi \\
\hline 3 & $\begin{array}{l}\text { Saya tidak pernah } \\
\text { meninggalkan pekerjaan saat } \\
\text { jam kerja }\end{array}$ & 0 & 1 & 9 & 0 & 0 & 29 & 2,90 & Cukup \\
\hline 4 & $\begin{array}{l}\text { Saya melaksanakan pekerjaan } \\
\text { sesuai dengan instruksi atasan }\end{array}$ & 0 & 2 & 8 & 0 & 0 & 28 & 2,80 & Cukup \\
\hline 5 & $\begin{array}{l}\text { Saya puas dengan pembagian } \\
\text { kerja yang dilakukan di } \\
\text { organisasi ini }\end{array}$ & 0 & 0 & 10 & 0 & 0 & 30 & 3,00 & Cukup \\
\hline \multicolumn{8}{|c|}{ Rata-Rata Skor } & 3,40 & Cukup \\
\hline
\end{tabular}


Dari Tabel 1 dapat dilihat jika rata-rata skor pra survei berdasarkan 5 pernyataan yang mengacu pada variabel semangat kerja berada pada kategori cukup, sehingga hal ini mengindikasikan karyawan memiliki semangat kerja yang belum maksimal dan perlu diketahui penyebabnya berdasarkan indikator indikator yang sesuai. Berdasarkan wawancara yang dilakukan pada manajer mengenai semangat kerja, dikatakan bahwa terdapat masalah yaitu ada beberapa karyawan tidak mengisi nomor barang yang akan dikirim dan salah memasukkan barang kiriman. Hal itu membuat karyawan pada bagian operasional bingung untuk proses pengiriman barang, sehingga barang yang sudah dikemas digudang harus dibongkar lagi. Kelalaian yang dilakukan karyawan ini merupakan hal yang mengindikasikan rendahnya semangat kerja yang dimiliki.

Berdasarkan yang telah dipaparkan, maka tujuan penelitian ini yakni guna menganalisis pengaruh komitmen organisasional, gaya kepemimpinan transformasional, dan kompensasi finansial terhadap semangat kerja. Pada penelitian ini diharapkan dapat memberikan manfaat secara teoritis maupun praktis. Secara teoritis diharapkan hasil penelitian ini dapat menambah ilmu pengetahuan dan kelengkapan teoritis ilmu manajemen sumber daya manusia. Sedangkan secara praktis, penelitian ini dapat dijadikan pertimbangan terutama bagi pihak manajemen di dalam merumuskan kebijakan perusahaan terutama yang terkait dengan semangat kerja sehingga perusahaan dapat mencapai tujuan secara optimal.

Bass dan Avolio (1995:49) menyatakan sebuah teori yaitu teori kepemimpinan transformasional yang lumrah menjadi rujukan para ahli dalam 
Made Febriani, Pengaruh Komitmen Organisasional.......

proyek penelitian, disertasi doktor serta buku pada bidang kepemimpinan transformasional. Teori tersebut menjelaskan bahwa kepemimpinan transformasional merupakan gaya kepemimpinan yang melibatkan pengikut atau bawahan, memberikan inspirasi bagi para pengikut atau bawahannya, dan berkomitmen dalam mewujudkan visi misi bersama dan tujuan bagi suatu organisasi atau perusahaan, serta memberikan tantangan bagi para pengikutnya untuk menjadi pemecah masalah yang inovatif, serta dapat mengembangkan kapasitas jiwa kepemimpinan setiap karyawan melalui pelatihan dan pendampingan.

Semangat kerja merupakan kegiatan melakukan pekerjaan secara lebih giat, dengan hal tersebut diharapkan segala pekerjaan yang dilakukan lebih cepat dapat diselesaikan sehingga akhirnya akan memperoleh hasil yang maksimal dan tentunya memuaskan (Netisemito, 2007:96). Menurut Tohardi (2006 : 427) semangat kerja merupakan kemampuan seseorang untuk melakukan kerjasama secara konsekuen dan giat dalam hal mengejar tujuan yang telah ditetapkan bersama.

Komitmen organisasional yaitu keinginan yang membuat karyawan untuk tetap bekerja dalam suatu organisasi atau perusahaan (Lamba dan Choudary, 2013). Griffin (2004 : 15) menyatakan komitmen organisasional merupakan sikap yang menggambarkan keterikatan seorang karyawan pada organisasi atau perusahaan. Pattnaik dan Santosh (2014) menyatakan komitmen organisasional dapat membangun pertumbuhan perusahaan. Robins and Judge (2015) menyatakan komitmen organisasional merupakan keadaan yang membuat 
karyawan berpihak terhadap tujuan organisasi dan memiliki keinginan sendiri untuk mempertahankan keanggotaannya. Bo Yu (2013) menyatakan komitmen organisasional dapat secara efektif untuk mengembangkan kreatifitas karyawan dalam perusahaan. Menurut Malik et al. (2013) komitmen organisasi akan meningkat jika karyawan merasa memiliki hak untuk terlibat atau ikut serta dalam pengambilan keputusan dan merasa tujuannya sesuai dengan tujuan organisasi. Luthans (2008:147) menyatakan komitmen organisasional adalah keinginan kuat yang dimiliki individu untuk mempertahankan keanggotaannya dalam organisasi.

Gaya kepemimpinan transformasional adalah gaya kepemimpinan yang dapat menginspirasi para bawahan atau pengikut untuk melampaui kepentingan diri sendiri demi kepentingan perusahaan (Robbins dan Judge, 2015 : 249). Kepemimpinan transformasional menurut pendapat Northouse (2013:176) ialah gaya kepemimpinan yang menekankan pada proses orang terlibat dengan orang lain lalu menciptakan suatu hubungan yang dapat meningkatkan motivasi baik dalam diri pemimpin maupun pengikut atau bawahannya. Chen et al. (2016) menyatakan dengan menerapkan kepemimpinan transformasional maka para pengikut akan dapat berinovasi pada perusahaan. Wuradji (2008:53) menyatakan mengembangkan visi dan misi yang jelas sehingga dapat dipahami pengikut merupakan pedoman untuk meningkatkan kepemimpinan transformasional. Gunawan dan Netra (2017) berpendapat kepemimpinan transformasional cenderung ke arah memberikan perhatian lebih kepada para pengikut atau bawahannya. Ljungholm (2014) berpendapat bahwa kepemimpinan transformasional akan dapat meningkatkan semangat kerja karyawan, pimpinan 
harus menunjukkan kepemimpinan transformasional serta terlibat langsung dalam hubungan dengan karyawan di suatu perusahaan. Dewi dan Mujiati (2015) menyatakan gaya kepemimpinan transformasional adalah gaya kepemimpinan yang inspiratif, dapat meningkatkan kinerja karyawan, dan dapat bertindak sebagai pemimpin yang efektif. Rahmi (2014) menyatakan seorang pemimpin dengan penerapan kepemimpinan transformasional akan memberikan pengaruh bagi para pengikut-pengikutnya dalam partisipasinya mencapai tujuan organisasi, pemecahan masalah dan pengambilan keputusan perusahaan.

Umar (2018:16) menyatakan kompensasi finansial adalah sesuatu yang diberikan pada karyawan dalam benuk gaji, bonus, premi, pengobatan, asuransi, dan lain-lain. Rivai (2011 : 741) berpendapat kompensasi finansial merupakan sesuatu yang diterima oleh karyawan sebagai pengganti kontribusi jasa karyawan pada organisasi atau perusahaan. Selain itu, Panggabean (2004 : 75) menyatakan kompensasi finansial merupakan penghargaan yang diberikan perusahaaan kepada karyawan sebagai balas jasa karena kontribusi yang mereka berikan kepada organisasi. Menurut Mangkuprawira (2002:196) kompensasi finansial ialah pembayaran pada karyawan berupa finansial yang langsung berupa uang, gaji, komisi, dan bonus, serta yang langsung berupa asuransi, bantuan sosial, uang cuti, uang pensiun, dan pendidikan. Sutrisno (2009) berpendapat kompensasi finansial merupakan kompensasi yang langsung dirasakan oleh penerimanya atau karyawan, yaitu berupa gaji dan tunjangan yang merupakan hak karyawan dan kewajiban suatu perusahaan untuk membayarnya. 
Hasil penelitian oleh Yudi dan Artha (2014), Kinjerski dan Skrypnek (2008), Trisna dan Sintaasih (2016), Ursa (2007), Windy (2012), Resi (2011) menemukan hasil yang sama bahwa komitmen organisasional berpengaruh positif dan signifikan terhadap semangat kerja. Jadi, berdasarkan studi empiris tersebut, dirumuskan hipotesis penelitian sebagai berikut.

$\mathrm{H}_{1}$ : Komitmen organisasional berpengaruh positif dan signifikan terhadap semangat kerja karyawan.

Hasil penelitiian oleh Ari dan Surya (2013), Yudi dan Artha (2014), Surya Rashmi Rawat (2015), Rio (2013) menemukan hasil yang sama bahwa gaya kepemimpinan transformasional berpengaruh positif dan signifikan terhadap semangat kerja. Berdasarkan studi empiris tersebut dirumuskan hipotesis sebagai berikut:

$\mathrm{H}_{2}$ : Gaya kepemimpinan transformasional berpengaruh positif dan signifikan terhadap semangat kerja karyawan.

Hasil penelitian oleh Arya dan Sudharma (2013), Petrescu dan Rob (2008), Linz et al. (2006), Noor Azmi et al. (2012), Sopiah (2013), Rose (2013), Manik dan Artha (2015), Gangga dan Sintaasih (2014), Yuniari dan Teni (2009) menemukan hasil yang sama bahwa kompensasi finansial berpengaruh positif dan signifikan terhadap semangat kerja. Jadi, berdasarkan studi empiris tersebut, dirumuskan hipotesis penelitian sebagai berikut.

$\mathrm{H}_{3}$ : Kompensasi finansial berpengaruh positif dan signifikan terhadap semangat kerja karyawan.

Untuk memperjelas arah penelitian yang telah dijelaskan sebelumnya, kerangka konseptual penelitian ini dapat disusun sebagai berikut. 


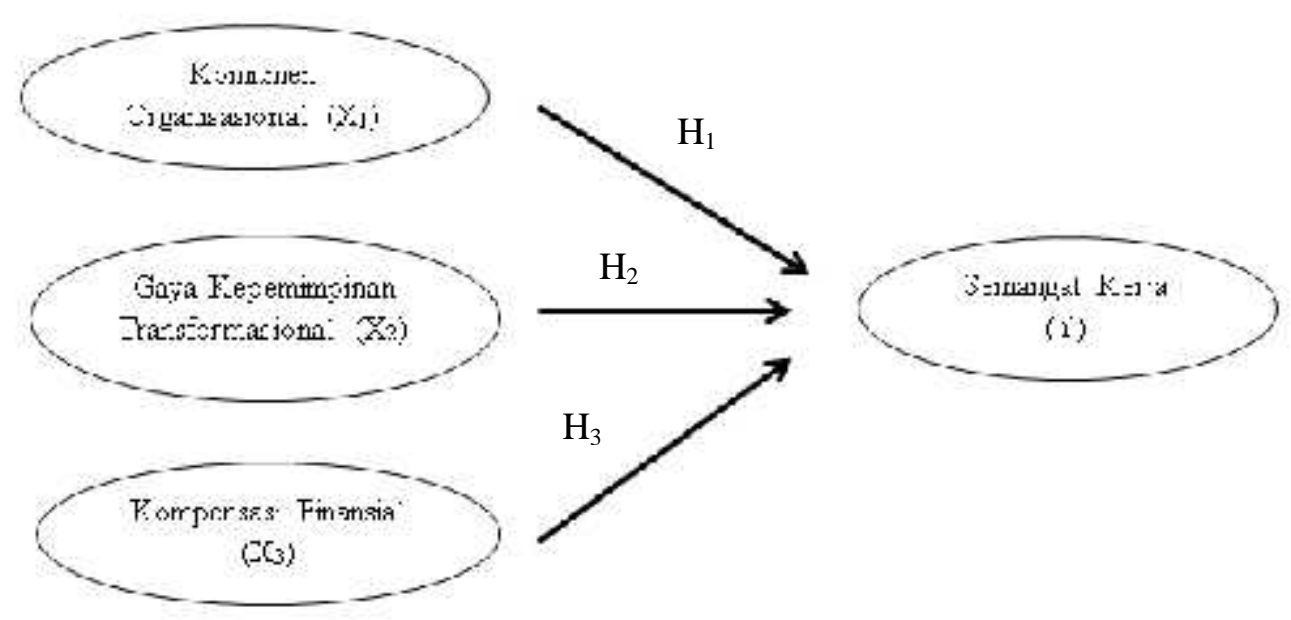

\section{Gambar 1. Kerangka Konseptual Penelitian}

\section{METODE PENELITIAN}

Penelitian menggunakan desain asosiatif yang menjelaskan pengaruh variabel bebas yaitu komitmen organisasional $\left(\mathrm{X}_{1}\right)$, gaya kepemimpinan transformasional $\left(\mathrm{X}_{2}\right)$, dan kompensasi finansial $\left(\mathrm{X}_{3}\right)$ terhadap semangat kerja (Y). Penelitian mengambil lokasi di PT. Surya Cemerlang Logistik. Populasi pada penelitian ini adalah 38 karyawan. Metode penentuan sampel yaitu saturated sampling, sehingga jumlah sampel adalah 38 karyawan. Metode pengumpulan data yang digunakan pada penelitian ini adalah wawancara dan penyebaran kuesioner. Pernyataan dalam kuesioner diukur dengan Skala Likert.

Tabel 2.

Alternatif Jawaban Responden

\begin{tabular}{ccc}
\hline Alternatif Jawaban (Simbol) & Alternatif Jawaban & Skorr \\
\hline STS & Sangat Tidak Setuju & 1 \\
TS & Tidak Setuju & 2 \\
N & Netral & 3 \\
S & Setuju & 4 \\
SS & Sangat Setuju & 5 \\
\hline
\end{tabular}

Sumber: Sugiyono, 2014 
Terdapat dua jenis data yang digunakan pada penelitian ini yaitu diantaranya data kuantitatif dan data kualitatif. Data kuantitatif berupa data dari jumlah karyawan yang dijadikan sampel serta skor jawaban dari responden dan data kualitatif berupa pendapat dari responden yang meliputi variabel bebas dan terikat. Berdasarkan sumbernya terdiri dari sumber primer dan sumber sekunder. Sumber primer berasal dari karyawan yang langsung memberikan jawaban atau skor berdasar pada variabel-variabel penelitian dalam kuisioner. Sedangkan sumber sekunder berasal dari data-data yang sudah tersedia pada perusahaan seperti sejarah berdirinya organisasi, data organisasi, struktur organisasi.

Kuesioner dipergunakan sebagai metode pengumpulan data primer, maka perlu dilakukan pengujian yaitu uji validitas dan reliabilitas agar kuesioner layak untuk digunakan. Syarat minimum agar dapat dianggap memenuhi syarat valid yaitu $r \geq 0,3$. Syarat minimum suatu variabel dianggap reliabel bila Cronbach's Alpha $\geq 0,60$. Regresi linear berganda dan uji asumsi klasik merupakan teknik analisis data yang digunakan.

\section{HASIL DAN PEMBAHASAN}

PT. Surya Cemerlang Logistik merupakan salah satu perusahaan pengiriman barang di Bali yang didirikan pada bulan Oktober 1999. Perusahaan logistik merupakan perusahaan yang menyediakan jasa pengiriman barang serta menyediakan jasa penyewaan gudang bagi perusahaan lain untuk menyimpan barangnya. Moto PT. Surya Cemerlang Logistik adalah “In Trust We Grow”, dengan moto tersebut maka kepercayaan dari pelanggan yang membuat perusahaan ini tumbuh dan berkembang hingga saat ini. 
PT. Surya Cemerlang Logistik adalah perusahaan yang bekerja pada bidang logistik yang melayani LCL \& FCL Service, Freight Forwarding Service, Tug \& Barge Service, Customs Brokerage, Warehousing. LCL (Less Container Load) berarti dalam satu container terdapat barang yang dimiliki oleh lebih dari satu pengirim, sedangkan FCL (Full Container Load) berarti dalam satu container terdapat barang yang dimiliki oleh satu pengirim. Freight Forwarding merupakan usaha dalam bidang pengangkutan barang. Tug \& Barge merupakan tongkang dan kapalnya yang biasanya digunakan di perairan dangkal. Customs Brokerage merupakan jasa yang mengurus seluruh keperluan logistik termasuk perizinan. Warehousing merupakan pergudangan yang disediakan oleh PT. Surya Cemerlang Logistik baik untuk disewakan maupun untuk keperluan perusahaan.

Struktur organisasi PT. Surya Cemerlang Logistik adalah struktur organisasi fungsional. Struktur organisasi fungsional merupakan struktur organisasi dimana pembagian kerja dilaksanakan berdasar pada fungsi-fungsi manajemen. Karyawan dikelompokkan pada satu unit kerja jika memiliki tugas yang sama.

PT. Surya Cemerlang Logistik dipilih menjadi lokasi penelitian sebab ditemukan adanya permasalahan mengenai semangat kerja karyawan berdasarkan hasil kuesioner pra survei. Pemilihan lokasi PT. Surya Cemerlang Logistik juga didasari oleh ketersediaan data dari perusahaan selain itu mampu untuk diolah.

Berdasarkan hasil penelitian yang telah dilakukan, diketahui gambaran karakteristik responden yang meliputi 4 aspek yaitu usia, jenis kelamin, pendidikan terakhir, masa kerja. Dirangkum berdasarkan Tabel 3 menunjukkan pada kategori usia responden sebagian besar 31-40 tahun yaitu sebanyak 20 orang. 
Artinya, karyawan PT. Surya Cemerlang Logistik telah memiliki sejumlah kualitas positif yang dibawa ke dalam pekerjaan, yaitu pengalaman serta komitmen karena usia berkaitan erat dengan tingkat kedewasaan dan kematangan seseorang dalam berpikir.

Pada kategori jenis kelamin, karyawan didominasi oleh tenaga kerja lakilaki. Artinya, karyawan PT. Surya Cemerlang Logistik menggunakan tenaga lakilaki yang dianggap mampu serta kuat menyelesaikan sebagaian pekerjaan dalam perusahaan.

Berdasarkan kategori pendidikan, sebagian besar merupakan tamatan S1. Artinya, karyawan PT. Surya Cemerlang Logistik telah memiliki karyawan yang sebagian besar telah menempuh pendidikan tinggi yang merupakan salah satu penentu kualitas sumber daya manusia di perusahaan.

Masa kerja karyawan sebagian besar 6-10 tahun. Artinya, karyawan PT. Surya Cemerlang Logistik memiliki loyalitas yang tinggi dan tingkat pengunduran diri yang rendah. Adapun karakteristik responden disajikan pada Tabel 3.

Hasil uji validitas disajikan pada Tabel 4 menunjukkan variabel semangat kerja, komitmen organisasional, gaya kepemimpinan transformasional, dan kompensasi finansial memiliki nilai Pearson's Correlation menunjukkan skor total seluruh butir pernyataan lebih besar dari $0,30(r>0,30)$ atau dapat dikatakan dalam instrumen penelitian tersebut valid atau layak digunakan untuk mengukur apa yang seharusnya diukur. 
Tabel 3.

Karakteristik Responden

\begin{tabular}{|c|c|c|c|c|}
\hline No & Karakteristik & Klasifikasi & $\begin{array}{l}\text { Jumlah } \\
\text { (Orang) }\end{array}$ & Persentase (\%) \\
\hline \multirow[t]{4}{*}{1} & Usia & $20-30$ & 10 & 26,32 \\
\hline & & $31-40$ & 20 & 52,63 \\
\hline & & $41-50$ & 8 & 21,05 \\
\hline & & Jumlah & 38 & 100 \\
\hline \multirow[t]{3}{*}{2} & Jenis Kelamin & Laki-laki & 33 & 86,84 \\
\hline & & Perempuan & 5 & 13,16 \\
\hline & & Jumlah & 38 & 100 \\
\hline \multirow[t]{6}{*}{3} & Pendidikan & SMA/SMK & 6 & 15,79 \\
\hline & & Diploma 1 (D1) & 5 & 13,16 \\
\hline & & Diploma 2 (D2) & 0 & 0,00 \\
\hline & & Diploma 3 (D3) & 10 & 26,32 \\
\hline & & Sarjana (S1) & 17 & 44,74 \\
\hline & & Jumlah & 38 & 100,00 \\
\hline \multirow[t]{4}{*}{4} & Masa Kerja & $1-5$ tahun & 10 & 26,32 \\
\hline & & 6-10 tahun & 20 & 52,63 \\
\hline & & 11-15 tahun & 8 & 21,05 \\
\hline & & Jumlah & 38 & 100,00 \\
\hline
\end{tabular}

Sumber : Data diolah, 2018

Berdasarkan Tabel 5 menunjukkan nilai dari Cronbach's Alpha masing masing variabel $>0,60$, hal ini berarti alat ukur tersebut memberikan hasil yang konsisten apabila alat ukur tersebut digunakan kembali untuk meneliti obyek yang sama.

Dalam mengukur kategori penilaian responden digunakan rantang penilaian yaitu: 1,00-1,80 (sangat rendah/sangat buruk) 1,81-2,61 (rendah/buruk) 2,61-3,40 (cukup) 3,41-4,20 (tinggi/baik) 4,21-5,00 (sangat tinggi /sangat baik). 
Tabel 4.

Hasil Uji Validitas

\begin{tabular}{cccc}
\hline Variabel & Indikator & Pearson Correlation & Keterangan \\
\hline \multirow{2}{*}{ Semangat Kerja } & Y.1 & 0,600 & Valid \\
Karyawan & Y.2 & 0,591 & Valid \\
(Y) & Y.3 & 0,728 & Valid \\
& Y.4 & 0,726 & Valid \\
& Y.5 & 0,577 & Valid \\
\hline Komitmen & X1.1.1 & 0,700 & Valid \\
Organisasional & X1.1.3 & 0,588 & Valid \\
(X1) & X1.2.1 & 0,762 & Valid \\
& X1.2.2 & 0,720 & Valid \\
& X1.2.3 & 0,683 & Valid \\
& X1.3.1 & 0,748 & Valid \\
& X1.3.2 & 0,714 & Valid \\
X1.3.3 & 0,615 & Valid \\
X2.1 & 0,456 & Valid \\
Transformasional & X2.2 & 0,529 & Valid \\
(X2) & X2.3 & 0,587 & Valid \\
& X2.4 & 0,846 & Valid \\
& X2.5 & 0,762 & Valid \\
Kompensasi Finansial & X3.1 & 0,809 & Valid \\
(X3) & X3.3 & 0,464 & Valid \\
& X3.4 & 0,633 & Valid \\
& & 0,678 & Valid \\
& & 0,749 & Valid \\
\hline
\end{tabular}

Sumber: Data diolah, 2018

Tabel 5.

Hasil Uji Reliabilitas

\begin{tabular}{ccc}
\hline Variabel & Cronbach's & Keterangan \\
& Alpha & \\
\hline Semangat Kerja Karyawan (Y) & 0,633 & Reliabel \\
Komitmen Organisasional (X1) & 0,830 & Reliabel \\
Gaya Kepemimpinan Transformasional (X2) & 0,753 & Reliabel \\
Kompensasi Finansial (X3) & 0,690 & Reliabel \\
\hline
\end{tabular}

Sumber: Data diolah, 2018

Tabel 6.

Deskripsi Variabel Semangat Kerja

\begin{tabular}{|c|c|c|c|c|c|c|c|c|c|}
\hline \multirow[t]{2}{*}{ No } & \multirow[t]{2}{*}{ Pernyataan } & \multicolumn{5}{|c|}{ Skor Jawaban } & \multirow{2}{*}{$\begin{array}{l}\text { Jumlah } \\
\text { Skor }\end{array}$} & \multirow{2}{*}{$\begin{array}{l}\text { Rata- } \\
\text { Rata }\end{array}$} & \multirow[t]{2}{*}{ Ket } \\
\hline & & 1 & 2 & 3 & 4 & 5 & & & \\
\hline 1 & $\begin{array}{l}\text { Tingkat kehadiran saya sudah } \\
\text { baik }\end{array}$ & 0 & 0 & 0 & 18 & 20 & 172 & 4,53 & $\begin{array}{l}\text { Sangat } \\
\text { Tinggi }\end{array}$ \\
\hline 2 & $\begin{array}{l}\text { Pekerjaan yang saya lakukan } \\
\text { selesai tepat waktu }\end{array}$ & 0 & 0 & 0 & 9 & 29 & 181 & 4.76 & $\begin{array}{l}\text { Sangat } \\
\text { Tinggi }\end{array}$ \\
\hline 3 & $\begin{array}{l}\text { Saya tidak pernah } \\
\text { meninggalkan pekerjaan saat } \\
\text { jam kerja }\end{array}$ & 0 & 1 & 17 & 16 & 4 & 137 & 3,61 & Tinggi \\
\hline
\end{tabular}

Bersambung... 
Lanjutan Tabel 6. Deskripsi Variabel Semangat Kerja

\begin{tabular}{|c|c|c|c|c|c|c|c|c|c|}
\hline \multirow[t]{2}{*}{ No } & \multirow[t]{2}{*}{ Pernyataan } & \multicolumn{5}{|c|}{ Skor Jawaban } & \multirow{2}{*}{$\begin{array}{l}\text { Jumlah } \\
\text { Skor }\end{array}$} & \multirow{2}{*}{$\begin{array}{l}\text { Rata- } \\
\text { Rata }\end{array}$} & \multirow[t]{2}{*}{ Ket } \\
\hline & & 1 & 2 & 3 & 4 & 5 & & & \\
\hline 4 & $\begin{array}{l}\text { Saya melaksanakan } \\
\text { pekerjaan sesuai dengan } \\
\text { instruksi atasan }\end{array}$ & 0 & 2 & 14 & 16 & 6 & 140 & 3,68 & Tinggi \\
\hline 5 & $\begin{array}{l}\text { Saya puas dengan pembagian } \\
\text { kerja yang dilakukan di } \\
\text { organisasi ini }\end{array}$ & 0 & 0 & 17 & 14 & 7 & 142 & 3,74 & Tinggi \\
\hline \multicolumn{8}{|c|}{ Rata-Rata Skor Variabel Semangat Kerja } & 4,06 & Tinggi \\
\hline
\end{tabular}

Sumber : Data primer diolah, 2018

Tabel 7.

Deskripsi Variabel Komitmen Organisasional

\begin{tabular}{|c|c|c|c|c|c|c|c|c|c|}
\hline \multirow[t]{2}{*}{ No } & \multirow[t]{2}{*}{ Pernyataan } & \multicolumn{5}{|c|}{ Skor Jawaban } & \multirow{2}{*}{$\begin{array}{l}\text { Jumlah } \\
\text { Skor }\end{array}$} & \multirow{2}{*}{$\begin{array}{l}\text { Rata- } \\
\text { Rata }\end{array}$} & \multirow[t]{2}{*}{ Ket } \\
\hline & & 1 & 2 & 3 & 4 & 5 & & & \\
\hline & Komitmen Afektif & & & & & & & & \\
\hline 1 & $\begin{array}{l}\text { Saya merasa ikut memiliki } \\
\text { organisasi }\end{array}$ & 0 & 3 & 15 & 17 & 3 & 134 & 3,53 & Tinggi \\
\hline 2 & $\begin{array}{l}\text { Saya merasa terikat secara } \\
\text { emosional dengan organisasi }\end{array}$ & 0 & 1 & 14 & 20 & 3 & 139 & 3,66 & Tinggi \\
\hline 3 & $\begin{array}{l}\text { Saya merasa menjadi bagian } \\
\text { dari organisasi ini }\end{array}$ & 0 & 1 & 16 & 17 & 4 & 138 & 3,63 & Tinggi \\
\hline 4 & $\begin{array}{l}\text { Komitmen Bersinambung } \\
\text { Saya merasa dengan bekerja } \\
\text { di organisasi ini merupakan } \\
\text { kesempatan terbaik. }\end{array}$ & 0 & 1 & 14 & 19 & 4 & 140 & 3,68 & Tinggi \\
\hline 5 & $\begin{array}{l}\text { Saya merasa rugi jika keluar } \\
\text { dari organisasi ini. }\end{array}$ & 0 & 1 & 16 & 15 & 6 & 140 & 3,68 & Tinggi \\
\hline 6 & $\begin{array}{l}\text { Saya menganggap jika bekerja } \\
\text { pada organisasi ini merupakan } \\
\text { suatu kebutuhan. } \\
\text { Komitmen Normatif }\end{array}$ & 0 & 2 & 14 & 14 & 8 & 142 & 3,74 & Tinggi \\
\hline 7 & $\begin{array}{l}\text { Saya loyal terhadap organisasi } \\
\text { ini. }\end{array}$ & 0 & 1 & 14 & 12 & 11 & 147 & 3,87 & Tinggi \\
\hline 8 & $\begin{array}{l}\text { Saya ingin menghabiskan sisa } \\
\text { karir di organisasi ini. }\end{array}$ & 0 & 2 & 12 & 9 & 15 & 151 & 3,97 & Tinggi \\
\hline 9 & $\begin{array}{l}\text { Saya tidak tertarik pada } \\
\text { tawaran pekerjaan organisasi } \\
\text { lain yang mungkin lebih baik } \\
\text { dari organisasi ini. }\end{array}$ & 0 & 0 & 0 & 6 & 32 & 184 & 4,84 & $\begin{array}{l}\text { Sangat } \\
\text { Tinggi }\end{array}$ \\
\hline
\end{tabular}
Sumber : Data primer diolah, 2018

Hasil pada Tabel 6 menunjukkan rata-rata skor 5 pernyataan pada variabel semangat kerja sebesar 4,06 yang berarti tinggi. Hal ini mengandung arti semangat kerja masih dikatakan tinggi. Distribusi jawaban responden terhadap variabel semangat kerja dengan nilai rata-rata tertingginya sebesar 4,76 pada 
pernyataan "Pekerjaan yang saya lakukan selesai tepat waktu" dan nilai rata-rata terendahnya sebesar 3,61 pada pernyataan "Saya tidak pernah meninggalkan pekerjaan saat jam kerja".

Hasil pada Tabel 7 menunjukkan rata-rata skor 9 pernyataan mengenai variabel komitmen organisasional sebesar 3,84 berarti kuat. Hal ini berarti apabila komitmen organisasional semakin kuat, maka semangat kerja yang dimiliki karyawan akan meningkat. Distribusi jawaban responden terhadap variabel komitmen organisasional dengan nilai rata-rata tertinggi sebesar 4,84 pada pernyataan "Saya tidak tertarik pada tawaran pekerjaan organisasi lain yang mungkin lebih baik dari organisasi ini.”, untuk nilai rata-rata terendahnya sebesar 3,53 pada pernyataan "Saya merasa ikut memiliki organisasi”.

Tabel 8.

Deskripsi Variabel Gaya Kepemimpinan Transformasional

\begin{tabular}{|c|c|c|c|c|c|c|c|c|c|}
\hline \multirow[t]{2}{*}{ No } & \multirow[t]{2}{*}{ Pernyataan } & \multicolumn{5}{|c|}{ Skor Jawaban } & \multirow{2}{*}{$\begin{array}{c}\text { Jumlah } \\
\text { Skor }\end{array}$} & \multirow{2}{*}{$\begin{array}{l}\text { Rata- } \\
\text { Rata }\end{array}$} & \multirow[t]{2}{*}{ Ket } \\
\hline & & 1 & 2 & 3 & 4 & 5 & & & \\
\hline 1 & $\begin{array}{lr}\text { Saya merasa pemimpin } \\
\text { memiliki kharisma dalam } \\
\text { menjalankan } & \\
\text { kepemimpinannya } & \text { dalam } \\
\text { organisasi. } & \end{array}$ & 0 & 0 & 15 & 16 & 7 & 144 & 3,79 & Baik \\
\hline 2 & $\begin{array}{lr}\text { Saya memiliki } & \text { kepercayaan } \\
\text { pemimpin } & \text { mampu } \\
\text { menumbuhkan } & \text { dan } \\
\text { membangkitkan } & \text { semangat } \\
\text { karyawan. } & \end{array}$ & 0 & 1 & 13 & 18 & 6 & 143 & 3,76 & Baik \\
\hline 3 & $\begin{array}{l}\text { Saya merasa pemimpin } \\
\text { memiliki naluri yang kuat } \\
\text { untuk membuat keputusan. }\end{array}$ & 0 & 1 & 12 & 18 & 7 & 145 & $3 ., 82$ & Baik \\
\hline 4 & $\begin{array}{l}\text { Saya merasa pemimpin } \\
\text { mampu memberikan dorongan } \\
\text { kepada karyawan untuk } \\
\text { bekerja lebih kreatif. }\end{array}$ & 0 & 1 & 14 & 15 & 8 & 144 & 3,79 & Baik \\
\hline 5 & $\begin{array}{l}\text { Saya merasa pemimpin } \\
\text { mampu membaur menjadi satu } \\
\text { dengan karyawan untuk } \\
\text { melakukan tugas. }\end{array}$ & 0 & 1 & 13 & 16 & 8 & 145 & 3,82 & Baik \\
\hline
\end{tabular}

Sumber : Data primer diolah, 2018 
Pada Tabel 8 menunjukkan rata-rata skor 5 pernyataan mengenai variabel gaya kepemimpinan transformasional sebesar 3,80 yang artnya baik. Hal ini berarti apabila gaya kepemimpinan transformasional semakin baik, maka semangat kerja karyawan PT. Surya Cemerlang Logistik akan meningkat. Distribusi jawaban responden variabel gaya kepemimpinan transformasional dengan nilai rata-rata tertingginya sebesar 3,82 pada pernyataan "Saya merasa pemimpin memiliki naluri yang kuat untuk membuat keputusan" dan "Saya merasa pemimpin mampu membaur menjadi satu dengan karyawan untuk melakukan tugas" Nilai rata-rata terendahnya 3,76 pada pernyataan "Saya memiliki kepercayaan pemimpin mampu menumbuhkan dan membangkitkan semangat karyawan".

Tabel 9.

Deskripsi Variabel Kompensasi Finansial

\begin{tabular}{|c|c|c|c|c|c|c|c|c|c|}
\hline \multirow[t]{2}{*}{ No } & \multirow[t]{2}{*}{ Pernyataan } & \multicolumn{5}{|c|}{ Skor Jawaban } & \multirow{2}{*}{$\begin{array}{c}\text { Jumlah } \\
\text { Skor }\end{array}$} & \multirow{2}{*}{$\begin{array}{l}\text { Rata- } \\
\text { Rata }\end{array}$} & \multirow[t]{2}{*}{ Ket } \\
\hline & & 1 & 2 & 3 & 4 & 5 & & & \\
\hline 1 & $\begin{array}{l}\text { Sistem pemberian gaji sudah } \\
\text { sesuai dengan pekerjaan yang } \\
\text { dibebankan kepada saya. }\end{array}$ & 0 & 0 & 9 & 13 & 16 & 159 & 4,18 & Baik \\
\hline 2 & $\begin{array}{l}\text { Tunjangan kerja yang } \\
\text { diberikan sudah sesuai dengan } \\
\text { tugas yang dibebankan kepada } \\
\text { saya. }\end{array}$ & 0 & 1 & 10 & 20 & 7 & 147 & 3,87 & Baik \\
\hline 3 & $\begin{array}{l}\text { Tunjangan kesehatan yang } \\
\text { diberikan sudah sesuai dengan } \\
\text { kebutuhan kesehatan saya. }\end{array}$ & 0 & 0 & 14 & 18 & 6 & 144 & 3,79 & Baik \\
\hline 4 & $\begin{array}{l}\text { Besarnya tunjangan hari raya } \\
\text { sudah sesuai dengan tingkat } \\
\text { kebutuhan hari raya. }\end{array}$ & 0 & 3 & 12 & 18 & 5 & 139 & 3,66 & Baik \\
\hline & Rata - Rata Skor Variabe & & & & an & & & $\mathbf{3 , 8 8}$ & Baik \\
\hline
\end{tabular}

Berdasarkan hasil tabulasi data jawaban responden terhadap pernyataan pernyataan tentang kompensasi finansial yang dijawab oleh 38 orang responden, maka dapat dibuat tabulasi jumlah jawaban seluruh responden. Hasil pada Tabel 9 
menunjukkan bahwa rata-rata skor dari 4 pernyataan mengenai variabel kompensasi finansial sebesar 3,88 yang artinya baik. Hal ini berarti apabila kompensasi finansial semakin baik, maka semangat kerja yang dimiliki karyawan PT. Surya Cemerlang Logistik akan meningkat. Distribusi jawaban responden terhadap variabel kompensasi finansial nilai rata-rata tertingginya 4,18 pada pernyataan "Sistem pemberian gaji sudah sesuai dengan pekerjaan yang dibebankan kepada saya." dan untuk nilai rata-rata terendahnya 3,66 pada pernyataan "Besarnya tunjangan hari raya sudah sesuai dengan tingkat kebutuhan hari raya".

Tabel 10.

Hasil Analisis Regresi Linier Berganda.

\begin{tabular}{cccccc}
\hline Model & \multicolumn{2}{c}{ Unstandardized Coefficients } & $\begin{array}{c}\text { Standardized } \\
\text { Coefficients }\end{array}$ & T & Sig. \\
\cline { 2 - 4 } & $\boldsymbol{B}$ & Std. Error & Beta & & \\
\hline (Constant) & 4,002 & 1,698 & & 2,357 & 0,024 \\
$\mathbf{X 1}$ & 0,219 & 0,059 & 0,463 & 3,717 & 0,001 \\
$\mathbf{X 2}$ & 0,235 & 0,081 & 0,306 & 2,909 & 0,006 \\
$\mathbf{X 3}$ & 0,276 & 0,124 & 0,253 & 2,226 & 0,033 \\
\hline $\mathbf{R}$ & 0,861 & & & & \\
$\mathbf{R}^{\mathbf{2}}$ & 0,741 & & & & \\
Adjusted $\mathbf{R}^{2}$ & 0,718 & & & & \\
F Statistik & 32,435 & & & & \\
Signifikansi & 0,000 & & &
\end{tabular}

Berdasarkan dari perhitungan analisis regresi linear berganda, maka didapatkan hasilnya sebagai berikut:

$$
\begin{aligned}
& Y=a+b_{1} X_{1}+b_{2} X_{2}+b_{3} X_{3}+e \\
& Y=4,002+0,219 X_{1}+0,235 X_{2}+0,276 X_{3}
\end{aligned}
$$

Nilai kolom B menunjukkan komitmen organisasional sebesar 0,219, gaya kepemimpinan transformasional sebesar 0,235, kompensasi finansial sebesar 0,276 dimana nilai tersebut mengindikasikan pengaruh positif. Artinya, jika salah 
satu nilai variabel bebas meningkat maka akan meningkatkan semangat kerjanya. Selain itu, keseluruhan variabel menunjukkan nilai signifikansi dibawah 0,05. Artinya secara parsial masing-masing variabel berpengaruh positif signifikan terhadap variabel terikat.

Uji ketepatan model dapat dilihat pada F statistik yang menunjukkan tingkat signifikansinya $0,000<0,05$, artinya model regressi linier berganda tepat digunakan untuk menguji variabel bebas komitmen organisaional, gaya kepemimpinan transformasional, kompensasi finansial terhadap variabel terikat yaitu semangat kerja. Uji Koefisien Determinasi / Nilai $\mathrm{R}^{2}$ sebesar 0,741 yang artinya sebesar 74,1 persen variasi semangat kerja dipengaruhi oleh komitmen organisasional, gaya kepemimpinan transformasional, dan kompensasi finansial, dan sisanya sebesar 25,9 persen dipengaruhi oleh faktor-faktor yang tidak digunakan dalam penelitian.

\section{Hasil Uji Asumsi Klasik}

Tabel 11. Hasil Uji Normalitas

\begin{tabular}{cc}
\hline & Unstandardized Residual \\
\hline $\mathbf{N}$ & 38 \\
Kolmogorov-Smirnov $\mathbf{Z}$ & 0,487 \\
Asymp. Sig. (2-tailed) & 0,972 \\
\hline
\end{tabular}

Sumber : Data diolah, 2018

Tabel 11 diatas menunjukkan hasil uji normalitas diperoleh hasil sebesar $0,972>0,05$ dimana hasil tersebut mengindikasikan model persamaan regresi tersebut berdistribusi normal.

Tabel 12 menunjukkan nilai Tolerance dan Variance Inflation Factor (VIF) variabel komitmen organisasional, gaya kepemimpinan transformasional, dan kompensasi finansial. 
Tabel 12. Hasil Uji Multikolinearitas

\begin{tabular}{ccc}
\hline Model & \multicolumn{2}{c}{ Colinearity Statistic } \\
\cline { 2 - 3 } & Tolerance & VIF \\
\hline Komitmen organisasional (X1) & 0,490 & 2,040 \\
Gaya kepemimpinan transformasional (X2) & 0,689 & 1,451 \\
Kompensasi Finansial (X3) & 0,590 & 1,694 \\
\hline
\end{tabular}

Sumber : Data diolah, 2018

Berdasarkan hasil analisis, dapat dilihat koefisien Tolerance variabel lebih besar dari 0,10 dan nilai Variance Inflation Factor (VIF) yang lebih kecil dari 10. Hasil ini mengindikasikan tidak terdapat gejala multikolinear dari model regresi yang dibuat.

Tabel 13.

Hasil Uji Heteroskedastisitas

\begin{tabular}{ccc}
\hline Model & Sig. & Keterangan \\
\hline Komitmen organisasional (X1) & 0,545 & Lolos Uji \\
Gaya kepemimpinan transformasional (X2) & 0,539 & Lolos Uji \\
Kompensasi Finansial (X3) & 0,413 & Lolos Uji \\
\hline
\end{tabular}

Sumber : Datadiolah, 2018

Tabel 13 menunjukkan hasil nilai signifikansi variabel komitmen organisasional, gaya kepemimpinan transformasional, kompensasi finansial lebih dari 0,05 yang berarti model regresi bebas dari gejala heteroskedastisitas.

\section{HASIL DAN PEMBAHASAN PENELITIAN}

Hasil penelitian menunjukkan komitmen organisasional berpengaruh positif signifikan terhadap semangat kerja yang berati apabila komitmen organisasional semakin baik maka semangat kerja yang dimiliki karyawan PT. Surya Cemerlang Logistik akan meningkat dan sebaliknya, semakin buruk komitmen organisasional maka semangat kerja yang dimiliki karyawan PT. Surya Cemerlang Logistik akan menurun. Hasil penelitian yang dilakukan ini sesuai dengan penelitian sebelumnya yang dilakukan oleh Yudi dan Artha (2014) yang dilakukan di The 
Stones Legian Bali Hotel menyatakan komitmen organisasional berpengaruh positif signifikan terhadap semangat kerja karyawan. Penelitian yang dilakukan oleh Kinjerski dan Skrypnek (2008) menyatakan semakin tinggi komitmen organisasional, maka semangat kerja juga akan semakin tinggi. Trisna dam Sintaasih (2016) dalam penelitiannya menemukan komitmen organisasional secara parsial berpengaruh positif dan signifikan terhadap semangat kerja. Ursa (2007) pada penelitiannya pada Staf Pengajar Universitas Gunadarma menyatakan bahwa komitmen organisasional berpengaruh positif signifikan terhadap semangat kerja. Penelitian yang dilakukan Windy (2012) pada perusahaan manufaktur di Surabaya menyatakan komitmen organisasional berpngaruh positif signifikan terhadap semangat kerja karyawan. Selain itu, Resi (2011) dalam penelitiannya menemukan komitmen organisasional berpengaruh positif signifikan terhadap semangat kerja karyawan.

Hasil penelitian ini menunjukkan gaya kepemimpinan transformasional berpengaruh positif signifikan terhadap semangat kerja artinya apabila gaya kepemimpinan transformasional semakin baik maka semangat kerja yang dimiliki karyawan PT. Surya Cemerlang Logistik akan meningkat dan sebaliknya, semakin buruk gaya kepemimpinan transformasional maka semangat kerja yang dimiliki karyawan PT. Surya Cemerlang Logistik akan menurun. Hasil penelitian ini sesuai dengan penelitian sebelumnya yang dilakukan oleh Ari dan Surya (2013) menyatakan gaya kepemimpinan transformasional berpengaruh positif signifikan terhadap semangat kerja. Penelitian yang dilakukan di The Stones Legian Bali Hotel oleh Yudi dan Artha (2014) menyatakan gaya kepemimpinan 
transformasional berpengaruh positif signifikan terhadap semangat kerja karyawan. Penelitian Putra dan Ayu (2013) menemukan bahwa komitmen organisasional dapat meningkatkan kinerja karyawan. Penelitian yang dilakukan oleh Surya (2015) di Pune City India menyatakan gaya kepemimpinan transformasional berpengaruh positif signifikan terhadap semangat kerja. Rio (2013) dalam penelitiannya menyatakan gaya kepemimpinan transformasional berpengaruh positif signifikan terhadap semangat kerja di Dinas Pertanian, Peternakan, dan Perikanan Kabupaten Siak

Hasil penelitian menunjukkan kompensasi finansial berpengaruh positif signifikan terhadap semangat kerja yang berarti apabila kompensasi finansial semakin baik maka semangat kerja yang dimiliki karyawan PT. Surya Cemerlang Logistik akan meningkat dan sebaliknya, semakin buruk kompensasi finansial maka semangat kerja yang dimiliki karyawan PT. Surya Cemerlang Logistik akan menurun. Hasil dari penelitian ini sesuai dengan penelitian sebelumnya yang dilakukan oleh Arya dan Sudharma (2013) pada CV. Leo Silver Batuyang Gianyar menyatakan kompensasi finansial berpengaruh positif signifikan terhadap semangat kerja karyawan. Petrescu and Rob (2008) mengatakan bahwa pemberian kompensasi finansial berpengaruh positif signifikan terhadap semangat kerja karyawan. Mita dan Subudi (2015) menyatakan kompensasi fnansial dapat meningkatkan kinerja karyawan. Linz et al. (2006) menyatakan kompensasi finansial memberikan kontribusi semangat kerja yang tinggi. Kompensasi finansial berpengaruh positif signifikan terhadap semangat kerja Noor Azmi et al. (2012). Menurut Sopiah (2013), hasil penelitiannya menunjukkan kompensasi 
finansial yang cukup baik diberikan akan mendorong karyawan dalam bekerja lebih giat lagi. Pemberian gaji dan bonus yang tinggi, akan mendorong semangat karyawan untuk bekerja pada suatu perusahaan Rose (2013). Selain itu menurut penlitian Manik dan Artha (2015) menyatakan kompensasi finansial berpengaruh positif signifikan terhadap semangat kerja karyawan.

\section{SIMPULAN DAN SARAN}

Simpulan yang diambil berdasar pada hasil analisis penelitian dan hasil pembahasan yang telah dipaparkan tersebut adalah komitmen organisasional, gaya kepemimpinan transfromasional, dan kompensasi finansial memiliki pengaruh positif dan signifikan terhadap semangat kerja.

Saran dilandasi berdasarkan hasil analisis penelitian yang dapat dilihat dari deskripsi variabel penelitian dengan nilai yang paling rendah dari masing-masing variabel yaitu semangat kerja, komitmen organisasional, gaya kepemimpinan transformasional, dan kompensasi finansial.

Pertama, pada variabel semangat kerja menunjukkan karyawan kurang taat pada waktu kerja, sehingga harus diperhatikan oleh pihak manajemen dan memperketat pengawasan pada karyawan misalnya dengan cara menambah fasilitas absen digital.

Kedua, pada variabel komitmen organisasional menunjukkan karyawan kurang merasa ikut memiliki organisasi, hal ini harus diperhatikan oleh pimpinan perusahaan misalnya dengan cara memberikan jenjang karir yang jelas. Jika perusahaan ingin berkembang, pihak manajemen harus memberikan jenjang karir yang jelas karena hal ini akan membuat karyawan totalitas dalam mengeluarkan 
kemampuannya dan nantinya akan membuat karyawan merasa ikut memiliki organisasi. Selain itu dengan cara mendengarkan dan menghargai ide - ide baru karyawan agar karyawan merasa diberi kesempatan untuk selalu mengembangkan kreativitas melalui ide-ide baru karyawan.

Ketiga, pada variabel gaya kepemimpinan transformasional menunjukkan karyawan kurang memiliki kepercayaan kepada pemimpin terhadap kemampuan menumbuhkan dan membangkitkan semangat karyawan, hal ini harus diperhatikan oleh pimpinan misalnya dengan cara memberikan apresiasi kepada karyawan yang berprestasi. Apresiasi dalam berbagai bentuk misalnya pemimpin meluangkan waktu untuk merayakan keberhasilan karyawan akan menumbuhkan dan membangkitkan semangat kerja karyawan.

Keempat, pada variabel kompensasi finansial menunjukkan tunjangan hari raya yang diberikan perusahaan kepada karyawan dianggap kurang membantu meringankan beban ekonomi karyawan, hal ini harus diperhatikan oleh pihak manajemen misalnya dengan cara lebih rutin memberikan tunjangan hari raya misalnya rutin diberikan setiap tahun pada hari raya besar nasional agar karyawan semakin bersemangat dalam melakukan tugas-tugasnya.

\section{REFERENSI}

Ari Suastika, Komang dan Made Surya Putra. (2013). Pengaruh kompensasi, gaya kepemimpinan transformasional dan komunikasi terhadap kepuasan kerja dan semangat kerja. E-Jurnal Manajemen Universitas Udayana, 1(4), hal: 17-31.

Arya Putra Dharmawan, I Gede dan I Nyoman Sudharma. (2013). Pengaruh Kepemimpinan, Kompensasi Finansial, dan Lingkungan Kerja Fisik terhadap Semangat Kerja Karyawan Pada CV. Leo Silver Batuyang Gianyar. E-Jurnal Manajemen Universitas Udayana, 2(9), pp: 11981202. 
Bass, Bernard M and Avolio, Bruce, J. (1995). Transformational Leadership and Organizational Culture. New York : Free Press.

Bo,Yu. (2013). The Influence Study of Transformational Leadership in University on Teachers' Organizational Commitment: The Constructions and Verifications of a Theoretical Model. Canadian Social Science, 9(4), pp: 126-137.

Chen, Lu, Wei Zheng, Baiyin Yang dan Shyaijiao Bai. (2016). Transformational Leadership Social Capital and Organizational Innovation. Leadership \& Organizational Development Journal, 37(7), pp: 843-859.

Dewi, Dimika Sari dan Ni Wayan Mujiati. (2015). Pengaruh The Big Five Personality dan Kepemimpinan Transformasional Terhadap Kinerja Karyawan di Karma Jimbaran Villa. E-Jurnal Manajemen Universitas Udayana, 4(4), hal: 930-942.

Gangga Pravasta, I.Gst Ngurah dan Desak Ketut Sintaasih. (2014). Kompensasi dan Motivasi: Pengaruhnya terhadap Semangat Kerja Karyawan PT. Tjendana Mandra Sakti Denpasar. E-Jurnal Manajemen Universitas Udayana, 3(5), hal: 1320-1341.

Gunawan, Indra I Kadek dan I Gusti Salit Ketut Netra. (2017). Pengaruh Kepemimpinan Transformasional dan Komitmen Organisasional Terhadap Organizational Citizenship Behavior Karyawan. E-Jurnal Manajemen Universitas Udayana, 6(4), hal: 2133-2160.

Griffin, Ricky W. (2004). Manajemen. Edisi 7. Jilid 1. Jakarta: Erlangga.

Hasibuan, Malayu SP. (2007). Manajemen Sumber Daya Manusia Dasar Dari Kunci Keberhasilan. Jakarta: CV Haji Masagung

Janet L.Henderson, and Ruben D.Nieto. (2008). Morale Levels Of First-Year Agricultural Education Teachers in Ohio. Internasional Journal of Agricultural Education, 8(5) pp: 112.

Kinjerski, V., and Skrypnek, B.J. (2008). The Promise of Spirit at Work: Increasing Job Satisfaction and Organizational Commitment and Reducing Turnover and Absenteeism in Long-Term Care. Journal of Gerontological Nursing, 34(10),pp: 17-25.

Lamba, Shruti, and Nirmala Choudary. (2013). Impact of HRM Practices on Organizational Commitment of Employees. International Journal of Advancementssin Research \& Technology, 2(4), pp: 407-423. 
Linz, Susan J., Linda K.Good, dan Patricia Huddleston. (2006). Worker Morale in Russia: an Exploratory Study. Journal of Managerial Psycology, 21(5), pp: 415-437.

Ljungholm, Doina Popescu. (2014). Transformational Leadership Behavior in Public Sector Organizations. Contemporary Readingsain Law and Social Justice, 6(1), pp: 76-81.

Luthans, Fred. (2006). Perilaku Organisasi. Edisi Kesepuluh. Alih Bahasa: Vivin A.Y, Shekar Purawanti. Yogyakarta: Andi.

Malik, Fahad., Chugtai, Salman., Iqbal,Zain., Ramzan, Muhammad. (2013). Does Psychological Empowerment Bring about Employee Commitment? Evidence from Telecomunication Sector of Pakistan. Journal of Business Studies Quarterly, 5(1), pp: 14-21.

Manik Swardika Yasa, I Ketut dan I Made Artha Wibawa. (2015). Pengaruh Kompensasi Finansial, Komunikasi Dan Lingkungan Kerja Fisik Terhadap Semangat Kerja Karyawan. E-Jurnal Manajemen Universitas Udayan, 4(3), hal: 750-763.

Mangkuprawira, Syafry. (2002). Manajemen Sumber Daya Manusia Strategi. Jakarta: Ghalia Indonesia.

Mita Febriani, Ni Luh dan Made Subudi. (2015). Pengaruh Kepemimpinan Transformasional, Budaya Organisasi, Dan Kompensasi Finansial Pada Kinerja Karyawan. E- Jurnal Manajemen Universitas Udayana, 4(5), hal: 1252-1270.

Nitisemito, A.S. (2007). Manajemen Personalia dan Operasi (Manajemen Sumber Daya manusia). Jakarta : Prestasi Publisher Indonesia.

Noor Azmi Ahmad, Azri Abdul Aziz, Syaquif Yasin Kamaruddin, Azdel Abdul Aziz \& Mohd Faeez Saiful Bakhtiar. (2012). The Influence Of Direct Financial Compensation Towards Future-Graduates Career Choice In Hotel Industry. Journal of Tourism, Hospitality and Culinary Arts, 4(3), pp:25- 26.

Northouse, Peter G. (2013). Kepemimpinan: Teori dan Praktik. Jakarta: PT.. Indeks Permata Puri Media.

Panggabean, Mutiara S. (2004). Manajemen Sumber Daya Manusia. Cetakan Kedua. Bogor Selatan: Ghalia Indonesia.

Pattnaik, Laxmiprada dan Santosh Kumar Tripathy. (2014). The Influence of Perceived Organisational Support on Organisational Commitment:An 
Empirical Study. Bi-annual Journal of Asian School of Business Management, 7(2), pp: 32-38.

Petrescu, Alina Ileana dan Rob Simmons. (2008). Human Resource Management Practices and Worker Job Satisfaction. International Journal of Manpower , 29 (7), pp: 651-667.

Putra, Yuda Perdana I Putu dan I Gusti Ayu Dewi Adnyani. (2013). Pengaruh Kepemimpinan Transformasional, Komunikasi dan Disiplin Kerja Terhadap Kinerja Karyawan Karoseri dan Body Repair Pada PT.. Merpati Bali. E-Jurnal Manajemen Universitas Udayana, 2(4), hal: 482-494.

Rahmi, B.Maptuhah. (2014). Pengaruh Kepemimpinan Transformasional Terhadap Organizational Citizenship Behavior dan Komitmen Organisasi Dengan Mediasi Kepuasan Kerja. E-Jurnal Manajemen Universitas Udayana, 3(2), hal: 330-350.

Resi Yudhaningsih. (2011). Peningkatan Efektivitas Kerja melalui Komitmen, Perubahan, dan Budaya Organisasi. Ragam Jurnal Pengembangan Humaniora , 11(1), hal: 40-50.

Rio Marpaung. (2013). Pengaruh kepemimpinan dan motivasi terhadap semangat kerja pegawai dinas Pertanian, Peternakan dan Perikanan Kabupaten Siak. Jurnal Ekonomi, 21(2), hal: 1-16.

Rivai, Veithzal. (2011). Manajemen Sumber Daya Manusia untuk Perusahaan. Edisi Kedua. Jakarta: Rajawali Pers.

Robbins, S.P dan Judge T.A. (2015). Perilaku Organisasi. Jakarta: Salemba Empat.

Rose, Richard. (2013). The Relationship of Pay to Job Attraction, Job Loyalty, and Performance for High Quality STEM Teachers. Revista Lusófona de Educação, 25(25), pp: 114.

Salem, Islam El-Bayoumi. (2015). Transformationa Leadership: Relationship to Job Stress And Job Burnout In Five-Star Hotels. SAGE Journal, 15(4), pp: 240-253.

Setyaningdyah, Endang, Umar Nimran, Kertahadi, dan Armanu Thoyih. (2013). The Effects of Human Resource Competence, Organisational Commitment and Transactional Leadership on Work Discipline, Job Statisfaction and Employee's Performance. Interdisciplinary Journal of Contemporary Research In Business, 5(4), pp: 140-153. 
Shahzad Khan dan Saqib Shahzad. (2013). Moderating Role of Procedural Justice and Empowerment in Transformational Leadership with its impact on Organizational Commitment. International Review of Management and Business Research, 2(3), pp: 847-852.

Sharma, Richa, Pooja Sharma dan V.K. Pandey. (2016). Motivation And Quality Of Work Life (Qwl) Programmes As Predictors Of Employee Commitment: A Study Of Service Organisation In Gwalior Region. Journal of Organisation and Human Behaviour; New Delhi, 5(1), pp: 3641.

Shim, Hee S, Youngoh Jo dan Larry T. Hoover. (2015). Police Transformational Leadership and Organizational Commitment. International Journal of Police Strategies \& Management., 38(4), pp: 754-774.

Siagian, Sondan P. (2007). Manajemen Sumber Daya manusia. Jakarta :Bumi Aksara.

Sopiah. (2013). The Effect of Compensations toward Job Satisfaction and Job Performance of Outsourcing Employee aof Syariah Banks in Malang Indonesa. International Journal of Learning \& Development, 3(2), pp: 88.

Srivalli, P dan Kota Neela Mani Kanta. (2016). Teaching Effectiveness: A Study On Moderation Effect Of Organisational Support And Organisational Commitment. Journal of Organisation and Human Behaviour, 5(1), pp: 28.

Surya Rashmi Rawat. (2015). Impact of Transformational Leadership over Employee Morale and Motivation. Indian Journal of Science and Technology, 8(6), pp: 25-34.

Sutrisno, Edy. (2010). Manajemen Sumber Daya Manusia. Jakarta : Kencana.

Tohardi, Ahmad. (2006). Manajemen Sumber Daya Manusia. Jakarta: Penerbit Prenhallindo Jakarta Darma Surya.

Trisna Suwandewi, Ni Nyoman dan Desak Ketut Sintaasih. (2016). Keadilan Organisasional dan Komitmen Organisasional: Efeknya Pada Organizational Citizenship Behavior. E-Jurnal Manajemen Universitas Udayana, 5(7), hal: 4453-4485.

Umar, Husein. (2008). Desain Penelitian MSDM dan Perilaku Karyawan, Jakarta: PT. Raja Grafindo Persada. 
Ursa Majorsy. (2007). Kepuasan Kerja, Semangat Kerja, dan Komitmen Organisasional pada Staf Pengajar Universitas Gunadarma. Jurnal Psikologi. 1(1), hal: 63-74.

Windy Aprilia Murty dan Gunasti Hudiwinarsih. (2012). Pengaruh Kompensasi, Motivasi, dan Komitmen Organisasional terhadap Kinerja Karyawan Bagian Akuntansi (Studi Kasus pada Perusahaan Manufaktur di Surabaya). Jurnal The Indonesian Accounting Review, 2(4), hal: 215-228.

Wuradji. (2008). The Educational Leadership (Kepemimpinan Transformasional). Yogyakarta: Gama Media.

Yingxiu Yang. (2014). Principals' Transformational Leadership In School Improvement. International Journal of Educational Management, 2(3), pp: 279-288.

Yudi Triyana, I Nyoman dan I Made Artha Wibawa. (2014). Pengaruh Gaya Kepemimpinan Transformasional, Insentif Finansial dan Komitmen Organisasional terhadap Semangat Kerja Karyawan The Stones Legian Bali Hotel. E-Jurnal Manajemen Universitas Udayana, 3(11), hal: 34353454.

Yuniari, Made dan Luh Gede Teni Waisnawini. (2009). Pengaruh Kompensasi dan Lingkungan Kerja serta Motivasi Kerja terhadap Semangat Kerja dan Kinerja Karyawan PT. BTDC Nusa Dua. Jurnal Bisnis dan Kewirausahaan, 5(2), hal: 144-152. 